\title{
Determination of the B-type Natriuretic Peptide Level as a Criterion for Abnormalities in Japanese Individuals in Routine Clinical Practice: The J-ABS Multi-center Study (Japan Abnormal BNP Standard)
}

\author{
Makoto Kawai ${ }^{1}$, Michihiro Yoshimura ${ }^{1}$, Masaki Harada ${ }^{2}$, Yuji Mizuno ${ }^{3}$, Shinya Hiramitsu ${ }^{4}$, \\ Mitsuyuki Shimizu ${ }^{1}$, Toru Shoda ${ }^{5}$ Koichiro Kuwahara ${ }^{2}$, Kenji Miyagishima ${ }^{4}$, \\ Kenji Ueshima ${ }^{6}$ and Kazuwa Nakao ${ }^{2}$
}

\begin{abstract}
Objective The present study was undertaken to establish a useful range for the B-type natriuretic peptide (BNP) level, with the ultimate goal of determining a cut-off BNP level that will make it possible to identify patients with clinically important organic heart disorders among patients encountered in clinical practice.

Methods A total of 11,967 outpatients were evaluated for this study, and, after applying the exclusion criteria, 361 patients were finally recruited for the analysis. Compared to the factors of gender and body mass index, aging was considered to be an indispensable factor in this analysis. The 'median' plasma BNP level was found to increase slowly with age, but remained lower than $30 \mathrm{pg} / \mathrm{mL}$, even in patients aged 60 years or older. In contrast, the overall '95th percentile' of the plasma BNP level in the patients younger than 60 years was $41 \mathrm{pg} / \mathrm{mL}$, which increased to $139.8 \mathrm{pg} / \mathrm{mL}$ in the patients aged 60 years or older.

Conclusion These findings suggest that the lower range of the BNP level allowing for identification of patients with clinically important organic heart disorders increases with age; however, it might be appropriate to adopt a level of approximately $40 \mathrm{pg} / \mathrm{mL}$, even in elderly patients, in order to avoid any possible age-related effects of diastolic dysfunction or other factors.
\end{abstract}

Key words: aging, plasma B-type natriuretic peptide level, multi-center study, organic heart disorders

(Intern Med 52: 171-177, 2013)

(DOI: 10.2169/internalmedicine.52.8704)

\section{Introduction}

B-type or brain natriuretic peptide (BNP) is a cardiac hormone (1) that has been utilized to detect early heart failure, estimate the severity of heart failure and predict the prognoses of cardiac patients (2-12). Measuring the plasma BNP level has been shown to be useful for determining the differential diagnosis in patients presenting with respiratory symp- toms or other problems $(13,14)$ and identifying asymptomatic patients with heart disease among individuals undergoing regular health checkups (15).

When the BNP level is used in clinical practice, its reference level (the criterion level) is $18.4 \mathrm{pg} / \mathrm{mL}$, as we have previously reported (16). The lower the plasma level of $\mathrm{BNP}$, the better the prognosis (10); thus, a level of $18.4 \mathrm{pg} /$ $\mathrm{mL}$ or lower is theoretically preferable in all patients. However, some clinical physicians in hospitals have expressed

${ }^{1}$ Division of Cardiology, Department of Internal Medicine, The Jikei University School of Medicine, Japan, ${ }^{2}$ Department of Medicine and Clinical Science, Kyoto University Graduate School of Medicine, Japan, ${ }^{3}$ Division of Cardiovascular Medicine, Kumamoto Kinoh Hospital, Kumamoto Aging Research Institute, Japan, ${ }^{4}$ Division of Cardiology, Department of Internal Medicine, Fujita Health University School of Medicine, Japan, ${ }^{5}$ Department of Laboratory Medicine, The Jikei University School of Medicine, Japan and ${ }^{6}$ EBM Research Center, Kyoto University Graduate School of Medicine, Japan

Received for publication July 29, 2012; Accepted for publication October 19, 2012

Correspondence to Dr. Makoto Kawai, cadmk@jikei.ac.jp 
opinions that $18.4 \mathrm{pg} / \mathrm{mL}$ may be too strict for diagnosing heart failure and significant organic heart disorders. Therefore, it has been suggested that a slightly higher cut-off level of plasma BNP would be preferable and more realistic for regular use in the clinical setting. Indeed, a considerable number of patients encountered in clinical practice, not only in cardiology clinics, but also in other departments, have demonstrated plasma BNP levels over $18.4 \mathrm{pg} / \mathrm{mL}$ without the presence of any organic heart disorders. It is therefore considered necessary to establish a new reference BNP level applicable for clinical use in hospitals.

The ultimate goal of this study was to determine a cut-off plasma BNP level that makes it possible to identify patients with clinically important organic heart disorders among the patients normally encountered in clinical practice. In other words, to identify a cut-off value that is the minimal level of plasma BNP that can exclude a diagnosis of clinicallyrelevant heart problems.

\section{Materials and Methods}

\section{Study population}

A total of 11,967 patients were recruited for this study among the individuals who visited the outpatient cardiology clinics of five facilities (Fujita Health University Hospital, Jikei University Hospital, Jikei University Kashiwa Hospital, Kumamoto Kinoh Hospital and Kyoto University Hospital) that participated in the J-ABS multicenter study (Japan Abnormal BNP Standard) between 2004 and 2008. This study was approved by the Ethics Committee of The Jikei University School of Medicine [20-238 (5528)] (and each committee of the other participating facilities, respectively).

\section{Exclusion and inclusion criteria}

The exclusion criteria included patients with structural heart disease without signs or symptoms of heart failure [stage B of the American College of Cardiology Foundation (ACC)/American Heart Association (AHA) heart failure classification guidelines for the evaluation and management of chronic heart failure in adults], more advanced stage $\mathrm{C}$ and D conditions meeting the ACC/AHA guidelines (13), ischemic heart disease (including patients with acute myocardial infarction, unstable angina pectoris or acute coronary syndrome and those undergoing coronary angiography or percutaneous coronary intervention), valvular heart disease (including patients with heart failure caused by moderate valvular disease and those scheduled to undergo surgery for valvular repair) or cardiomyopathy (dilated cardiomyopathy, hypertrophic cardiomyopathy, restrictive cardiomyopathy and secondary cardiomyopathies). Patients who met any of these criteria were excluded from the analysis.

In more detail, we excluded patients based on the following criteria in this study: (1) patients with an ejection fraction $(\mathrm{EF})<55 \%$, a left ventricular end-diastolic dimension $($ LVDd) $\geq 60 \mathrm{~mm}$, a left atrial dimension (LAD) $\geq 40 \mathrm{~mm}$ and a left ventricular mass index (LVMI) $>125 \mathrm{~g} / \mathrm{m}^{2}$ in men and $110 \mathrm{~g} / \mathrm{m}^{2}$ in women on echocardiography, (2) patients with a current and overt history of atrial fibrillation (including patients with a history of catheter ablation, implantable cardioverter-defibrillators or cardiac resynchronization therapy and patients with pacemakers or syncope), (3) patients with a compromised renal function (estimated glomerular filtration rate: eGFR $<60 \mathrm{~mL} / \mathrm{min} / 1.73 \mathrm{~m}^{2}$ ), (4) patients with evident inflammatory disease (e.g. pericarditis, myocarditis, infective endocarditis, pneumonia, urinary tract infections or sepsis) and (5) patients with moderate or severe anemia.

Patients with risk factors for heart disease (diabetes mellitus, hypertension, dyslipidemia, obesity and other conditions) and patients receiving treatment for these risk factors (stage A of the ACC/AHA heart failure guidelines) were included in the analysis unless they met any of the exclusion criteria listed above. Based on the patient's height and weight on admission, the body mass index (BMI) was calculated as the weight $(\mathrm{kg})$ divided by the square $\left(\mathrm{m}^{2}\right)$ of the height.

\section{Measurement of plasma BNP}

The plasma BNP level was measured by a contract laboratory using an MI02 Shionogi BNP instrument (Shionogi \& Co., Ltd., Osaka, Japan) or within each facility using the E Test TOSOH II (Tosoh Corporation, Tokyo, Japan). Good correlations were found between the measurements obtained with the Shionoria BNP (the gold standard for BNP measurement) and those obtained using the other method at the individual facilities, with correlation equations and coefficients of $\mathrm{y}=1.01 \mathrm{x}-4.223(\mathrm{r}=0.981)$ and $\mathrm{y}=0.97 \mathrm{x}+3.83(\mathrm{r}=$ 0.996), respectively, with the Shionoria BNP denoted. The intra-day reproducibility (determined using the coefficient of variation: $\mathrm{CV}$ ) was 1.6-3.6 and 2.0-2.7, respectively, while the inter-day reproducibility (CV) was 1.3-4.5 and 1.4-3.2, respectively $(17,18)$. Each blood sample was collected into an EDTA-2Na-treated blood sampling tube that was centrifuged at a low temperature to separate the plasma for the assay.

\section{Doppler echocardiogram and renal function}

In this study, Doppler echocardiograms were obtained for all patients at each facility, and the EF was measured in the M-mode (Teichholz formula) and/or using quantitative 2D (biplane modified Simpson's rule) methods for each subject. The correlation among the methods was excellent. Calculation of the LV mass on echocardiogram uniformly employed the equation for estimation reported by Deveraux et al. (19). The body surface area (BSA) used for the LVMI calculation was derived from the actual height and body weight of each patient. The LVMI and BSA were calculated using the following Devereux equation and Du Bois equation (20), respectively:

$$
\begin{aligned}
\text { LVMI }= & \left\{\left\{1.04 \times\left[(\mathrm{LVDd}+\mathrm{PW}+\mathrm{IVS})^{3}-\mathrm{LVDd}^{3}\right]\right\}-13.6\right\} \\
& \times \mathrm{BSA}^{-1}\left(\mathrm{~g} / \mathrm{m}^{2}\right) \\
\mathrm{BSA}= & \text { height }^{0.725} \times \text { body weight } \\
&
\end{aligned}
$$


Table 1. Clinical Characteristics of the Study Population

\begin{tabular}{|c|c|c|c|c|c|c|c|}
\hline \multirow{2}{*}{ Factors } & \multicolumn{2}{|l|}{ Male } & \multicolumn{2}{|c|}{ Female } & \multicolumn{3}{|c|}{ Total } \\
\hline & $\mathrm{n}$ & mean $\pm \mathrm{SD}$ & $\mathrm{n}$ & mean $\pm \mathrm{SD}$ & $\mathrm{n}$ & mean $\pm \mathrm{SD}$ & $\min , \max$ \\
\hline$\overline{\mathrm{BNP}(\mathrm{pg} / \mathrm{mL})}$ & 197 & $20.02 \pm 26.53$ & 164 & $26.22 \pm 34.56$ & 361 & $22.84 \pm 30.55$ & $\overline{(2.0,268.2)}$ \\
\hline Age (years old) & 197 & $48.2 \pm 18.3$ & 164 & $52.8 \pm 17.9$ & 361 & $50.3 \pm 18.3$ & $(12,90)$ \\
\hline Height $(\mathrm{cm})$ & 196 & $168.78 \pm 6.91$ & 162 & $155.42 \pm 5.76$ & 358 & $162.73 \pm 9.24$ & $(140.0,183.0)$ \\
\hline Weight (kg) & 196 & $65.85 \pm 11.15$ & 162 & $53.95 \pm 10.49$ & 358 & $60.47 \pm 12.36$ & $(29.7,105.0)$ \\
\hline BMI $\left(\mathrm{kg} / \mathrm{m}^{2}\right)$ & 196 & $23.06 \pm 3.27$ & 162 & $22.36 \pm 4.30$ & 358 & $22.74 \pm 3.78$ & $(13.7,41.4)$ \\
\hline $\operatorname{BSA}\left(\mathrm{m}^{2}\right)$ & 196 & $1.750 \pm 0.160$ & 162 & $1.512 \pm 0.133$ & 358 & $1.642 \pm 0.190$ & $(1.10,2.14)$ \\
\hline Systolic blood pressure (mm Hg) & 187 & $126.7 \pm 16.6$ & 159 & $124.3 \pm 19.7$ & 346 & $125.6 \pm 18.1$ & $(82,198)$ \\
\hline Diastolic blood pressure $(\mathrm{mm} \mathrm{Hg})$ & 187 & $75.4 \pm 10.5$ & 159 & $73.6 \pm 13.4$ & 346 & $74.5 \pm 12.0$ & $(37,120)$ \\
\hline Heart rate $(/ \mathrm{min})$ & 182 & $71.7 \pm 13.2$ & 159 & $74.3 \pm 12.7$ & 341 & $73.0 \pm 13.0$ & $(37,127)$ \\
\hline eGFR $\left(\mathrm{mL} / \mathrm{min} / 1.73 \mathrm{~m}^{2}\right)$ & 197 & $89.32 \pm 22.92$ & 164 & $90.48 \pm 22.37$ & 361 & $89.85 \pm 22.65$ & $(60.2,259.1)$ \\
\hline Serum cleatinine $(\mathrm{mg} / \mathrm{dL})$ & 197 & $0.78 \pm 0.13$ & 164 & $0.57 \pm 0.09$ & 361 & $0.69 \pm 0.15$ & $(0.4,1.1)$ \\
\hline $\mathrm{EF}(\%)$ & 197 & $66.68 \pm 6.34$ & 164 & $67.24 \pm 6.80$ & 361 & $66.93 \pm 6.55$ & $(55.0,90.0)$ \\
\hline $\mathrm{LAD}(\mathrm{mm})$ & 197 & $32.35 \pm 4.96$ & 164 & $31.49 \pm 4.57$ & 361 & $31.96 \pm 4.80$ & $(9.2,40.0)$ \\
\hline LVDd (mm) & 197 & $45.96 \pm 3.74$ & 164 & $42.80 \pm 4.14$ & 361 & $44.52 \pm 4.22$ & $(27.3,54.8)$ \\
\hline $\operatorname{LVMI}\left(\mathrm{g} / \mathrm{m}^{2}\right)$ & 196 & $93.94 \pm 16.22$ & 162 & $84.60 \pm 14.84$ & 358 & $89.72 \pm 16.27$ & $(36.5,124.1)$ \\
\hline
\end{tabular}

Table 2. Percentile BNP Values for Gender Difference

\begin{tabular}{|c|c|c|c|}
\hline & Male $(n=197)$ & Female $(n=164)$ & $\mathrm{p}$ \\
\hline & Median $\left(25^{\text {th }}, 75^{\text {th }}, 95^{\text {th }}\right.$ percentiles $)$ & Median $\left(25^{\text {th }}, 75^{\text {th }}, 95^{\text {th }}\right.$ percentiles $)$ & Wilcoxon rank sum test \\
\hline $\mathrm{BNP}(\mathrm{pg} / \mathrm{mL})$ & $10.4(4.9,24.0,71.9)$ & $16.4(9.0,29.7,84.8)$ & 0.0003 \\
\hline
\end{tabular}

BNP: B-type natriuretic peptide

To evaluate the renal function, the following equation for estimation announced in May 2008 by the Japanese Society of Nephrology was employed instead of the conventionally used Modification of Diet in Renal Disease (MDRD) Study equation and the Cockcroft-Gault equation for conversion (21). Patients with an eGFR $<60 \mathrm{~mL} / \mathrm{min} / 1.73 \mathrm{~m}^{2}$ were excluded from the analysis:

$\mathrm{eGFR}=194 \times \operatorname{age}^{-0.287} \times \operatorname{Scr}^{-1.094}(\times 0.739$, for women $)(\mathrm{mL} /$ $\min / 1.73 \mathrm{~m}^{2}$ )

\section{Statistical analysis}

Continuous variables are expressed as the mean \pm standard deviation (SD) or percentile values (from the 25 th percentile to the 95th percentile). The correlations from the analysis of the plasma BNP levels (logarithmically converted data) and other various measurements were expressed as the correlation coefficients (r). Comparisons of two groups were made using the Wilcoxon rank-sum test where necessary. All tests were two-tailed, and $\mathrm{p}<0.05$ was considered to be statistically significant.

\section{Results}

\section{Characteristics of the final study population}

Among the 11,967 recruited patients, the final number of patients was reduced to only 361 (3\%) after applying the exclusion criteria. Among the finally adopted study population, 197 patients were men and 164 patients were women, and their mean age was $50.3 \pm 18.3$ (mean \pm SD) years ranging from 12 to 90 years. All other clinical characteristics are shown in Table 1.

\section{Plasma BNP levels and gender differences}

The plasma BNP levels (median values) were significantly higher in the women than in the men, as shown in Table 2.

\section{Plasma BNP levels and BMI}

Fig. 1 shows the relationship between the plasma BNP levels and BMI. The logarithmically-converted plasma BNP levels decreased as the BMI increased, and the BNP level was found to be significantly correlated with BMI ( $\mathrm{n}=358$, $\mathrm{r}=-0.239, \mathrm{p}<0.0001)$.

\section{Plasma BNP levels and age}

Fig. 2 shows the relationship between the plasma BNP levels and age. The logarithmically-converted plasma BNP levels increased with age and were found to be significantly correlated with age $(\mathrm{n}=361, \mathrm{r}=0.5168, \mathrm{p}<0.0001)$. As shown in Table 3, the 95th percentile of the plasma BNP level gradually increased with age; however, it increased at a value of three to four times in the patients aged 60 years or older compared to that observed in the other age groups. For patients younger than 60 years of age, the overall 95th percentile of the plasma BNP level was $41 \mathrm{pg} / \mathrm{mL}$ (Tables 3, 4). 


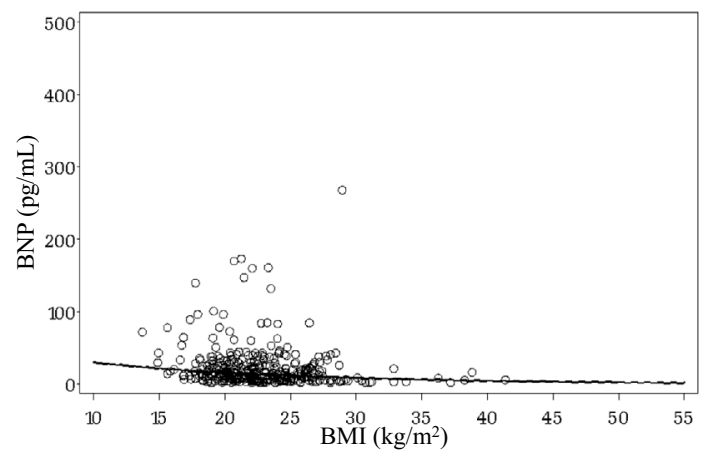

Figure 1. Relationship between the plasma BNP level and BMI. BNP: B-type natriuretic peptide, BMI: body mass index. Solid line: the curve yielded from exponential conversion of the regression line for logarithmically-converted data $(n=358$, $r=-0.239, p<0.0001$ ).

\section{Discussion}

In the present study, we attempted to determine a reference level for the plasma BNP level that would be useful for identifying patients with clinically important organic heart disorders among patients encountered in routine clinical practice. This cut-off value would be considered the minimum plasma BNP value used to identify patients with stage B or higher ACC/AHA heart failure (13).

\section{Relationship between the plasma BNP levels and gender}

The present study demonstrated a significant effect of gender on the plasma BNP level (Tables 1-3), consistent with the findings of a previous report (22). We found the plasma BNP levels (the mean or percentile of the values) to be slightly higher in women than in men (Tables 1,2 ). In each age group, the median plasma BNP level was slightly higher in the women than in the men, and the absolute difference in this parameter between the women and men was approximately $6 \mathrm{pg} / \mathrm{mL}$. One reason why gender influences the BNP level may involve hormonal regulation of estrogen (22), as Redfield et al. reported that hormone replacement therapy (HRT) increased the plasma BNP levels in each of their age-matched female patient groups.

\section{Relationship between the plasma BNP levels and BMI}

BMI was also identified to be a significant factor determining the plasma BNP level in the present study (Fig. 1). Consistent with the previous finding that the plasma BNP levels tend to be lower in obese individuals (23), the present study revealed a negative correlation between the plasma BNP level and obesity (Fig. 1). This finding suggests that increases in obesity can suppress the plasma BNP levels. However, the BMI-related change observed in the present study population was relatively small. If heart failure becomes advanced, then the influence of obesity on the plasma

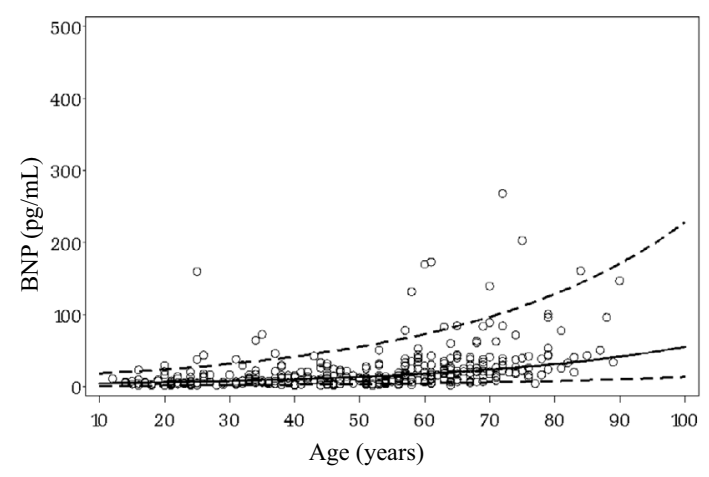

Figure 2. Relationship between the plasma BNP level and age. BNP: B-type natriuretic peptide. Solid line: the curve yielded from exponential conversion of the regression line for logarithmically-converted data. Broken line: the curve yielded from exponential conversion of the $95 \%$ prediction interval for logarithmically-converted data $(n=361, r=0.5168, p<$ 0.0001).

BNP level may become stronger (24).

\section{Relationship between the plasma BNP levels and age}

Compared to gender and BMI, age was identified to be a more important factor in this analysis. When analyzing the 'median' plasma BNP level, this parameter was found to increase slowly with age $[6.4 \mathrm{pg} / \mathrm{mL}$ at ages of 29 years or younger (the $\leq 29$ years group); $8.4 \mathrm{pg} / \mathrm{mL}$ at ages between 30 and 39 years (the $30-39$ years group); $10.6 \mathrm{pg} / \mathrm{mL}$ at ages between 40 and 49 years (the $40-49$ years group); 11.1 $\mathrm{pg} / \mathrm{mL}$ at ages between 50 and 59 years (the 50-59 years group); $25.0 \mathrm{pg} / \mathrm{mL}$ at ages of 60 years or older (the $\geq 60$ years group)] (data not shown in Results) and remained lower than $30 \mathrm{pg} / \mathrm{mL}$, even in the patients aged 60 years or older (Fig. 2). Significant differences in the BNP levels among the four age groups under the age of 60 years were found: between the $\leq 29$ years group and the 30-39 years group, and between the $\leq 29$ years group and the $50-59$ years group (using the Wilcoxon rank-sum test, data not shown). These results indicate that the BNP levels in the $\leq 29$ years group were lower than those in the other age groups, although there were no significant differences in the BNP levels in the remaining age groups (30-39, 40-49 and 50-59). On the other hand, the '95th percentile' of the plasma BNP level rose more markedly with age; however, it did not uniformly increase in the four age groups under 60 years of age (Table 3), reaching $139.8 \mathrm{pg} / \mathrm{mL}$ in the patients aged 60 years or older (Fig. 2, Table 3). These findings indicate that the plasma BNP level does not uniformly exhibit age-related elevations in all individuals, although the overall percentage of individuals with elevated plasma BNP levels does increase with age. While it is known that the physiological function gradually decreases with age, it remains unclear whether the decrease should be considered an illness or an inevitable natural change.

Therefore, in the present study, we excluded some of the 
Table 3. 95th Percentile BNP Values for Each Age Group

\begin{tabular}{lcccccc}
\hline $95^{\text {th }}$ percentile BNP $(\mathrm{pg} / \mathrm{mL}),(\mathrm{n})$ & Age: -29 & Age: $30-39$ & Age: $40-49$ & Age: $50-59$ & Age: 40-59 & Age: $60-$ \\
\hline ALL & $29.6,(62)$ & $46.2,(48)$ & $33.3,(47)$ & $50.9,(76)$ & $41.0,(123)$ & $139.8,(128)$ \\
Male & $21.3,(39)$ & $64.4,(31)$ & $31.9,(26)$ & $53.0,(39)$ & $42.7,(65)$ & $84.4,(62)$ \\
Female & $37.9,(23)$ & $46.2,(17)$ & $33.3,(21)$ & $44.0,(37)$ & $39.4,(58)$ & $147.2,(66)$ \\
\hline
\end{tabular}

BNP: B-type natriuretic peptide

Table 4. 95th Percentile BNP Values for Each Age Group

\begin{tabular}{lrr}
\hline & Age: -59 & Age: 60- \\
\hline Number & 233 & 128 \\
$95^{\text {th }}$ percentile BNP $(\mathrm{pg} / \mathrm{mL})$ & 41.0 & 139.8 \\
\hline BNP: B-type natriuretic peptide & &
\end{tabular}

data for the elderly group from the analysis because we wanted to exclude patients with diastolic dysfunction caused by aging as much as possible. Reductions in the diastolic function in the Japanese population tend to become evident at ages over 60 years $(25,26)$; therefore, we calculated the 95th percentile plasma BNP level for individuals younger than 60 years of age and found it to be $41 \mathrm{pg} / \mathrm{mL}$. Indeed, elderly persons with a well maintained diastolic function who demonstrate low plasma BNP levels generally show good prognoses $(27,28)$. It thus appears appropriate to adopt a level of approximately $40 \mathrm{pg} / \mathrm{mL}$ as a useful reference level for patients younger than 60 years of age.

\section{The cut-off levels of plasma BNP in other studies}

A plasma BNP level of approximately $40 \mathrm{pg} / \mathrm{mL}$ is equivalent to the cut-off levels reported in other studies of individuals undergoing thorough health checkups $(15,29)$. These studies attempted to determine the plasma BNP level that is useful for identifying patients with heart disease by means of receiver operating characteristic (ROC) analyses and obtained cut-off levels of 40 or $50 \mathrm{pg} / \mathrm{mL}$. The cut-off level obtained in the present study is identical to these reported levels, despite the fact that our study used a different study population. Therefore, a value of approximately 40 $\mathrm{pg} / \mathrm{mL}$ is considered to be highly significant.

In other countries, plasma BNP level measurements have been reported to be useful in the differential diagnosis of patients presenting with heart disease when the cut-off level was set at $80-100 \mathrm{pg} / \mathrm{mL}(30,31)$. Because the plasma BNP levels obtained using the measurement system generally used in the United States are approximately 1.6-fold the levels obtained using the Japanese system (32), the reported non-Japanese cut-off levels are also considered to be equivalent to a cut-off level of approximately $50-62.5 \mathrm{pg} / \mathrm{mL}$ in Japan. This provides further evidence that a cut-off level of approximately $40 \mathrm{pg} / \mathrm{mL}$ is useful.

\section{Significance of BNP values of $18.4 \mathrm{pg} / \mathrm{mL}$ and 40 $\mathrm{pg} / \mathrm{mL}$}

The cut-off level obtained in this study is not inconsistent with the existing cut-off level (not more than $18.4 \mathrm{pg} / \mathrm{mL}$ or $20 \mathrm{pg} / \mathrm{mL}$ ). The cut-off level 'not more than $18.4 \mathrm{pg} / \mathrm{mL}$ ' was derived from healthy individuals, and hence, only pertains to healthy individuals. Moreover, this cut-off value could be considered the borderline between a no-risk population and subjects with stage A ACC/AHA heart failure (13). In contrast, the cut-off level ' $40 \mathrm{pg} / \mathrm{mL}$ ' obtained in the present study indicates that the levels above this value are very likely to be associated with cardiac abnormalities or heart failure on existing tests and examinations. In other words, this cut-off level is thought to be the minimal plasma BNP level necessary to detect clinical heart abnormalities as well as the approximate border between stage A and stage B of the ACC/AHA heart failure classification (13). We therefore propose that this cut-off level be considered a 'standard for plasma BNP abnormality' for clinical utilization and verification. Fortunately, this standard is applicable not only in routine clinical practice, but also in cardiac screening performed during health checkups, thorough health checkups, critical care and other clinical situations, as described in the previous reports discussed above.

\section{Limitations}

First, BNP is not the only marker of organic heart disorders, and it is sometimes impossible to rule out heart diseases if patients demonstrate levels of less than $40 \mathrm{pg} / \mathrm{mL}$. For example, there may be patients whose plasma BNP levels are less than $40 \mathrm{pg} / \mathrm{mL}$ but who nevertheless have ischemic heart diseases, including acute coronary syndrome, apical hypertrophic cardiomyopathy, pericarditis, infective endocarditis, sarcoidosis, amyloidosis, cardiac tamponade, etc. In addition, caution should be exercised in patients with unwitnessed symptomless arrhythmias (e.g. paroxysmal atrial fibrillation), since the plasma BNP levels are known to fluctuate widely in such individuals. Other examinations should therefore be used in combination with the BNP level, as appropriate.

Second, among the exclusion criteria used in this study, the LVMI may need to be considered. Cardiac hypertrophy arises as an early compensatory phenomenon in the presence of either poor blood pressure control or a compromised renal function and is a strong risk factor for the occurrence of cardiovascular events (33). When designing exclusion crite- 
ria related to cardiac hypertrophy, we noted that few reports have been published on LVMI in the Japanese population $(25,26)$. We therefore determined the cut-off LVMI levels reported in approximately 50 papers dealing with LVMI in Japanese subjects published over the past decade and found the cut-off levels based on the European Society of Cardiology Guidelines (2003), i.e., men $>125 \mathrm{~g} / \mathrm{m}^{2}$ and women $>110 \mathrm{~g} / \mathrm{m}^{2}$, to have been the most frequently applied (34). However, the influence of cardiac hypertrophy may still not be sufficiently excluded even when using an LVMI cut-off level and other exclusion criteria.

Finally, this research study targeted outpatients who visited the cardiovascular unit at each hospital. Almost all of the patients had some form of cardiac disease, and only $3 \%$ $(361 / 11,967)$ of the total outpatients who visited the clinic had no-event cardiovascular disorders. Therefore, it was impossible to draw a ROC curve from the present data. Moreover, in this study, the level of $40 \mathrm{pg} / \mathrm{mL}$ was not investigated with regard to its significant for determining subsequent prognosis. A prognostic study should be performed in another series of patients. In addition, the age-related reference levels of plasma BNP for use in detecting heart abnormalities, including diastolic dysfunction, might also need to be determined in another series of studies.

\section{Conclusion}

We herein attempted to determine a reference level for the plasma BNP level that would be useful for identifying patients with clinically important structural heart disease among patients encountered in routine clinical practice. The lower range of BNP allowing for identification of patients with clinically important organic heart disorders increases with age; however, it might be appropriate to adopt a level of approximately $40 \mathrm{pg} / \mathrm{mL}$, even in elderly patients, in order to avoid possible age-related effects of diastolic dysfunction or other factors. It is advisable to explore the underlying diseases in patients whose plasma BNP levels exceed this standard.

The authors state that they have no Conflict of Interest (COI).

\section{Acknowledgement}

We thank Dr. Hirofumi Yasue, Director General, Division of Cardiovascular Medicine, Kumamoto Kinoh Hospital, Kumamoto Aging Research Institute for providing valuable advice regarding the discussion of this study.

\section{References}

1. Sudoh T, Kangawa K, Minamino N, et al. A new natriuretic peptide in porcine brain. Nature 332: 78-81, 1988.

2. Mukoyama M, Nakao K, Hosoda K, et al. Brain natriuretic peptide as a novel cardiac hormone in humans. Evidence for an exquisite dual natriuretic peptide system, atrial natriuretic peptide and brain natriuretic peptide. J Clin Invest 87: 1402-1412, 1991.

3. Yasue H, Yoshimura M, Sumida H, et al. Localization and mechanism of secretion of B-type natriuretic peptide in comparison with those of A-type natriuretic peptide in normal subjects and patients with heart failure. Circulation 90: 195-203, 1994.

4. Morita E, Yasue H, Yoshimura M, et al. Increased plasma levels of brain natriuretic peptide in patients with acute myocardial infarction. Circulation 88: 82-91, 1993.

5. Omland T, Aakvaag A, Bonarjee VV, et al. Plasma brain natriuretic peptide as an indicator of left ventricular systolic function and long-term survival after acute myocardial infarction. Comparison with plasma atrial natriuretic peptide and $\mathrm{N}$-terminal proatrial natriuretic peptide. Circulation 93: 1963-1969, 1996.

6. Tsutamoto T, Wada A, Maeda K, et al. Attenuation of compensation of endogenous cardiac natriuretic peptide system in chronic heart failure: prognostic role of plasma brain natriuretic peptide concentration in patients with chronic symptomatic left ventricular dysfunction. Circulation 96: 509-516, 1997.

7. Berger R, Huelsman M, Strecker K, et al. B-type natriuretic peptide predicts sudden death in patients with chronic heart failure. Circulation 105: 2392-2397, 2002.

8. Richards AM, Nicholls MG, Espiner EA, et al. B-type natriuretic peptides and ejection fraction for prognosis after myocardial infarction. Circulation 107: 2786-2792, 2003.

9. Suzuki S, Yoshimura M, Nakayama M, et al. Plasma level of Btype natriuretic peptide as a prognostic marker after acute myocardial infarction: a long-term follow-up analysis. Circulation 110: 1387-1391, 2004.

10. Wang TJ, Larson MG, Levy D, et al. Plasma natriuretic peptide levels and the risk of cardiovascular events and death. N Engl J Med 350: 655-663, 2004.

11. Di Angelantonio E, Chowdhury R, Sarwar N, et al. B-type natriuretic peptides and cardiovascular risk: systematic review and metaanalysis of 40 prospective studies. Circulation 120: 2177-2187, 2009.

12. Daniels LB, Clopton P, Jiang K, et al. Prognosis of stage A or B heart failure patients with elevated B-type natriuretic peptide levels. J Card Fail 16: 93-98, 2010.

13. Hunt SA, Abraham WT, Chin MH, et al. American College of Cardiology Foundation; American Heart Association. 2009 Focused update incorporated into the ACC/AHA 2005 Guidelines for the Diagnosis and Management of Heart Failure in Adults A Report of the American College of Cardiology Foundation/American Heart Association Task Force on Practice Guidelines Developed in Collaboration With the International Society for Heart and Lung Transplantation. J Am Coll Cardiol 53: e1-e90, 2009.

14. Dickstein K, Vardas PE, Auricchio A, et al. 2010 Focused Update of ESC Guidelines on device therapy in heart failure: an update of the 2008 ESC Guidelines for the diagnosis and treatment of acute and chronic heart failure and the 2007 ESC guidelines for cardiac and resynchronization therapy. Developed with the special contribution of the Heart Failure Association and the European Heart Rhythm Association. Eur Heart J 31: 2677-2687, 2010.

15. Niinuma H, Nakamura M, Hiramori K. Plasma B-type natriuretic peptide in a multiphasic health screening program. Cardiology $\mathbf{9 0}$ : 89-94, 1998.

16. Yasue $H$, Yoshimura M, Jougasaki M, et al. Plasma levels of brain natriuretic peptide in normal subjects and patients with chronic heart failure: measurement by immunoradiometric assay (IRMA). Horm Clin 41: 397-403, 1993.

17. Shimosako K, Takahashi A, Saito T, et al. Evaluation of automated chemiluminescent enzyme immunoassay analyzer exclusive kit "MI02 Shionogi BNP". Jpn J Med Pharm Sci 53: 355-360, 2005.

18. Ohta A, Kikuchi $\mathrm{H}$, Oguchi $\mathrm{S}$, et al. Analysis of brain natriuretic peptide measured using E Test "TOHSO" II (BNP). J Clin Lab Inst Reag 28: 255-261, 2005.

19. Devereux RB, Alonso DR, Lutas EM, et al. Echocardiographic assessment of left ventricular hypertrophy: comparison to necropsy 
findings. Am J Cardiol 57: 450-458, 1986.

20. Du Bois D, Du Bois EF. A formula to estimate the approximate surface area if height and weight be known. 1916. Nutrition 5: 303-311, 1989.

21. Matsuo S, Imai E, Horio M, et al. Collaborators developing the Japanese equation for estimated GFR. Revised equations for estimated GFR from serum creatinine in Japan. Am J Kidney Dis $\mathbf{5 3}$ : 982-992, 2009.

22. Redfield MM, Rodeheffer RJ, Jacobsen SJ, et al. Plasma brain natriuretic peptide concentration: impact of age and gender. J Am Coll Cardiol 40: 976-982, 2002.

23. Wang TJ, Larson MG, Levy D, et al. Impact of obesity on plasma natriuretic peptide levels. Circulation 109: 594-600, 2004.

24. Nakane T, Kawai M, Komukai K, et al. Contribution of extracardiac factors to the inconsistency between plasma b-type natriuretic peptide levels and the severity of pulmonary congestion on chest x-rays in the diagnosis of heart failure. Intern Med 51: 239-248, 2012.

25. Okura Y, Ohno Y, Suzuki K, et al. Characterization of outpatients with isolated diastolic dysfunction and evaluation of the burden in a Japanese community: Sado Heart Failure Study. Circ J 71: 10131021, 2007.

26. Watanabe S, Suzuki N, Kudo A. Influence of aging on cardiac function examined by echocardiography. Tohoku J Exp Med 207: 13-19, 2005.

27. Wallén $T$, Landahl $S$, Hedner $T$, et al. Brain natriuretic peptide predicts mortality in the elderly. Heart 77: 264-267, 1997.

28. Ueda R, Yokouchi M, Suzuki T, et al. Prognostic value of high plasma brain natriuretic peptide concentrations in very elderly persons. Am J Med 114: 266-270, 2003.

29. Nakamura M, Endo H, Nasu M, et al. Value of plasma B type natriuretic peptide measurement for heart disease screening in a Japanese population. Heart 87: 131-135, 2002.

30. Dao Q, Krishnaswamy P, Kazanegra R, et al. Utility of B-type natriuretic peptide in the diagnosis of congestive heart failure in an urgent-care setting. J Am Coll Cardiol 37: 379-385, 2001.

31. McCullough PA, Nowak RM, McCord J, et al. B-type natriuretic peptide and clinical judgment in emergency diagnosis of heart failure: analysis from Breathing Not Properly (BNP) Multinational Study. Circulation 106: 416-422, 2002.

32. Fischer Y, Filzmaier K, Stiegler H, et al. Evaluation of a new, rapid bedside test for quantitative determination of B-type natriuretic peptide. Clin Chem 47: 591-594, 2001.

33. Levy D, Garrison RJ, Savage DD, et al. Prognostic implications of echocardiographically determined left ventricular mass in the Framingham Heart Study. N Engl J Med 322: 1561-1566, 1990.

34. European Society of Hypertension-European Society of Cardiology Guidelines Committee. 2003 European Society of Hypertension-European Society of Cardiology guidelines for the management of arterial hypertension. J Hypertens 21: 1011-1053, 2003.

(C) 2013 The Japanese Society of Internal Medicine http://www.naika.or.jp/imonline/index.html 